

\title{
A DINÂMICA NATURAL DAS FLORESTAS
}

\author{
NATURAL DYNAMICS OF THE RAIN FORESTS
}

\section{Euler Sandeville}

Arquiteto e urbanista com formação em Arte Educação, pós-graduado em Ecologia, mestre e doutor em Arquitetura e Urbanismo. Professor do Grupo Paisagem e Ambiente do Departamento de Projeto da FAUUSP, do qual é atualmente coordenador e professor orientador da área de concentração Paisagem e Ambiente do curso de pós-graduação da Faculdade de Arquitetura e Urbanismo da USP.

e-mail: sandeville@gmail.com

\begin{abstract}
"O grupamento só existe em função do meio, da história geológica do país (paleogeografia). Está em perpétuo desequilibrio, faz-se e desfaz-se para ceder o lugar a outro."
\end{abstract}

Grassé, 1929'

\section{RESUMO}

Este artigo elabora uma revisão de teorias sobre o processo de sucessão ecológica, relevantes para uma adequada compreensão da dinâmica natural da vegetação no Brasil. A valorização da natureza é, hoje, um tema recorrente, e a possibilidade de entendê-la como um processo em mudança contínua é uma das bases da abordagem científica da paisagem e pré-requisito para seu estudo, interpretação e mesmo para aplicação em trabalhos de planejamento ambiental. A aplicação das teorias de sucessão ecológica nos ecossistemas tropicais procura entender os processos de regeneração natural e recuperação de matas nativas. $\bigcirc$ artigo é parte dos capítulos de minha tese de doutorado² e dá continuidade ao artigo intitulado "A Divisão Natural das Paisagens Brasileiras", publicado em Paisagem e Ambiente, n. 18. Este trabalho terá continuidade em um terceiro artigo que discutirá conceitos e técnicas de recuperação de áreas degradadas com vegetação nativa, nos quais os conceitos aqui apresentados são aplicados.

Palavras-chave: Sucessão ecológica, florestas tropicais, ecossistemas tropicais, paisagens naturais brasileiras.

\begin{abstract}
This article elaborates a revision of relevant aspects of the ecology to understanding the natural dynamics of the vegetation in Brazil. The nature's valorization is today an appealing theme. The possibility of understanding it in succession process is one of the bases of the scientific approach of the landscape and prerequisite, in the current knowledge model, for its study, interpretation and even for application in works of environmental planning. This paper is an overview about tropical ecosystems theory, ecological succession as a basis to understanding natural process in forest regenerations and for native forest restoration. The article is part of the chapters of my doctoral theory, and gives sequence to the article "The Natural Regions of Brazilian Landscapes" published in Paisagem e Ambiente, n. 18. It will be continued in next future for another paper discussing concepts and techniques to restoration and recuperation of degraded areas with native species, where these concepts are applied.
\end{abstract}

Key words: Ecological succession, tropical rain forests, tropical ecosystems, brazilian natural landscapes. 


\section{INTRODUÇÃO}

O quadro natural de como macrotipologias de paisagem distribuem-se pelo território discutido no artigo "A Divisão Natural das Paisagens Brasileiras" (Revista Paisagem e Ambiente, n. 18), se não for complementado por outros conhecimentos sobre as dinâmicas naturais, pode passar a errônea impressão de alterações ocorrerem ou apenas serem significativas nos tempos geológicos, como, por exemplo, no caso dos enclaves vegetacionais. Desse modo, as formações vegetais poderiam ser percebidas, a um observador distante ou desavisado, como dotadas de uma grande homogeneidade em decorrência da estrutura fisionômica dessa formação, ou ainda sugerir que os estágios mais avançados de sucessão ecológica caracterizem-se por uma estabilidade que não se encontra na natureza.

Acontece que são muito dinâmicos e complexos esses processos. $\bigcirc$ ciclo de vida e morte, cujo ápice tem sido visto como a reprodução, dando a medida da importância da flor nas ciências biológicas, é vertiginosamente dinâmico. Na verdade, toda a ação conservacionista atual, bem como os estudos ecológicos, centram-se, em grande medida, na compreensão dessa sucessão da vida nos ambientes. Portanto, para montar um painel do conhecimento contemporâneo sobre a natureza, é necessário justapormos a esse quadro regional a dinâmica dos processos internos que parecem presidi-los, expresso, em parte, pelo conceito de sucessão ecológica. Restaria, ainda, uma necessária abordagem complementar, a qual não será fornecida neste artigo, abarcada pelos estudos das dinâmicas e fluxos na paisagem, cuja compreensão mais rica, entretanto, depende, em minha opinião, de sua articulação com a natureza dos processos internos aos ecossistemas. Dar a conhecer um pouco das teorias sobre a sucessão ecológica em ambientes tropicais a arquitetos paisagistas é a contribuição a que se propõe este artigo.

\section{SUCESSÃO ECOLÓGICA}

O termo sucessão designa que as comunidades são dinâmicas e não-estáveis no tempo. Um dos primeiros marcos teóricos foi o trabalho de Clements em 1916: Plant sucession $^{3}$. Esse autor estava convencido que a vegetação apresenta um desenvolvimento previsível e passível, portanto, de ser interpretado por leis científicas ${ }^{4}$. Estabeleceu o conceito de clímax determinado pelo clima regional (clímax climático, ou monoclímax 5 ). O conceito de Clements, ou teoria do monoclímax, é a comunidade evoluir de estágios iniciais de colonização de uma área, por meio da substituição sucessiva de grupos florísticos, até o estágio maduro ou de equilíbrio ${ }^{\circ}$.

A teoria de Clements foi ultrapassada, mas forneceu o paradigma para o entendimento sobre sucessão ${ }^{7}$. Apesar dos críticos à teoria de Clements, Odum ${ }^{8}$ a considera uma das teses mais importantes da ecologia, em sua percepção de haver um processo em nível de comunidade e não apenas de indivíduos. Como veremos, está exatamente aí um dos pontos mais polêmicos nas teorias sobre sucessão ecológica. 
A sucessão é geralmente definida como uma mudança direcional na composição florística e na fisionomia de uma área onde o clima permanece constante, através do tempo 9 , isto é, trata-se do processo de substituição de uma comunidade por outra, no sentido de uma menor ou maior complexidade, embora os modelos que descrevem tanto a substituição quanto a estrutura dinâmica dessas comunidades permaneça em questão.

Destaque-se que o conceito de sucessão não se aplica a mudanças ocorridas em milhares de anos, devido ao fato de as condições climáticas não haverem permanecido constantes. Para Walter ${ }^{10}$, só é possível falar em sucessão quando o desenvolvimento de uma comunidade de plantas pode ser acompanhado em período relativamente curto ou estabelecido com bases no secamento de corpos d'água, substituição em área de dunas, de montanhas rochosas ou de rochas vulcânicas jovens e, em poucos casos, com base em informações de perfis do solo. Podem ocorrer também zonações devidas a mudanças de fatores ambientais, não no tempo, mas no espaço; nesses casos considera que só hipoteticamente podem ser consideradas séries ecológicas. Essas posições o levam a rejeitar a teoria da sucessão primária e, conseqüentemente, a de clímax de comunidade, em prol de um conceito por ele definido em 1954, de vegetação zonal. $\bigcirc$ termo estágios sucessionais só se aplicaria efetivamente à sucessão secundária, quando os estágios de desenvolvimento da vegetação natural ou de adaptação a novos hábitats podem ser diretamente seguidos ${ }^{11}$.

Odum entende haver, na sucessão secundária, uma substituição mais ou menos contínua de espécies no tempo (seres), chamada por Egler, em 1954, de florística de revezamento. Cita Nicholson \& Monk os quais, em 1974, determinaram a riqueza e uniformidade vegetal para quatro formas de vida (herbáceas, trepadeiras, arbustos e árvores) em estádios serais da sucessão em campos abandonados do piemonte da Geórgia, EUA. Observaram que a riqueza aumentou rapidamente em cada estrato após seu estabelecimento e em velocidade menor durante o resto da sucessão; a uniformidade aumentou quase imediatamente para um nível máximo, mudando muito pouco depois.

Embora o conceito de sucessão seja considerado básico em ecologia, os modelos teóricos para descrevê-la aparentam deparar-se, ainda, com dificuldades quando confrontados com os processos naturais. Koch \& Ward ${ }^{12}$ esperavam encontrar uma correspondência com a realidade em uma área, na Austrália, no modelo de Egler (initial floristic), segundo o qual estão representados, no banco de sementes do solo, todas as espécies estabelecidas na área, apenas havendo alternância na dominância, conforme o estágio sucessional a que pertencem as espécies. Portanto, seria de esperar-se que a flora a qual se estabeleceria já conteria a maioria das espécies que viriam a dominar no clímax da comunidade. Estudos posteriores apontaram um caminho diferente, com poucas espécies componentes da floresta clímax, representadas no banco de sementes, o qual tenderia, então, a gerar uma flora diferente da floresta clímax após a reabilitação.

Segundo Luken ${ }^{13}$, os estudos sobre a sucessão procuraram, inicialmente, uma compreensão do processo a partir de modelos universais, mas estariam, atualmente, deslocando-se para o entendimento da participação dos indivíduos e populações na 
sucessão. Menciona, como exemplo, Pickett e outros autores que, em 1987, propuseram uma hierarquia baseada na contribuição de indivíduos de cada espécie e nos fatores que controlam sua viabilidade e performance no sítio.

Mattes e Martins ${ }^{14}$, tomando como base Finegan ${ }^{15}$, reconhecem duas tendências nessas teorias acima mencionadas. Uma denominada "holismo", derivada de Clements e outra derivada de Gleason, questionando o modelo sugerido por Clements, em 1917 e 1926, denominada "reducionista", correspondendo esta, talvez, ao que Odum denomina de teorias da causação ${ }^{16}$. A primeira teria foco no estudo do ecossistema (propriedades emergentes): "A sucessão é interpretada, teleologicamente, como um processo de desenvolvimento de um ecossistema de estabilidade máxima e de eficiência máxima na utilização dos recursos. As mudanças sucessionais são sempre ordenadas, previsíveis e determinadas (...)."17 Ainda seguindo os autores mencionados, nesse enfoque a presença de espécies ou grupos delas tornariam o ambiente propício para o grupo seguinte, facilitando as mudanças sucessionais ("facilitação").

Para a teoria reducionista, o processo não seria determinístico ou uma propriedade emergente, mas função de variações apresentadas pelas populações no tempo, não ocorrendo em etapas distintas, "e sim como mudanças irregulares e variáveis das populações através do tempo, faltando a ordenação e uniformidade" ${ }^{18}$. Para Finmegan, nenhum dos dois modelos explica observações de campo, sendo necessária uma terceira teoria, já que "os reducionistas sustentam que a sucessão ocorre devido à existência de um espectro de tipos de ciclos de vida, os quais são a base para o modelo da composição florística inicial (IFC)", desconsiderando mecanismos importantes como dispersão de sementes ${ }^{19}$.

Com base em Luken, elaboramos um quadro que sintetiza essas diversas posições (Quadro 1). Esse autor parece considerar a teoria de Connel e Slatyer a explanação recente mais influente. Connel e Slatyer, em 1977, apresentaram três modelos: facilitação, tolerância e inibição. Luken, então, adota como o modelo que melhor descreve a realidade - o da inibição. Inibição "is where established species inhibit the invasion and growth of all potential competitors during the entire duration of a successional pathway. There was much evidence in support of this model. Many failed attempts to speed the invasion of trees into established vegetation will attest to the fact that inhibition is a reality", Luken, 1990, p. 5.

modelo da facilitação preconiza que as espécies do início dos seres mudam as condições de existência, preparando o caminho para invasores posteriores; o modelo de inibição preconiza que as primeiras espécies resistem à invasão até serem substituídas por causa da competição, predação e perturbação, segundo explicação desses modelos por Odum, 1988, p. 297. A opção de Luken pelo último modelo reflete uma tensão teórica já mencionada na abordagem da sucessão, entre enfoques que privilegiam os processos no nível do ecossistema (biocenose) e aqueles que privilegiam aspectos ligados ao indivíduo e à população no processo de sucessão.

Odum, entretanto, parece ter uma visão diversa daquela de Luken, apresentada acima: "Embora se pudesse supor, logicamente, que tanto os processos a nível de ecossis- 
tema quanto aqueles a nível de população contribuem para as progressões sucessionais complexas descritas nesta seção, alguns ecologistas escolheram argumentar em prol

Quadro 1: Várias teorias sobre a sucessão, segundo Luken ${ }^{20}$

\begin{tabular}{l|l|l|l|l}
\hline Autores & \multicolumn{2}{l}{ Etapas } \\
\hline Clements & Migração & Ecesis & Competição & Estabilização \\
\hline $\begin{array}{l}\text { Relay floristics } \\
\text { (Grupos florísticos) }\end{array}$ & $\begin{array}{l}\text { Estabelecimento das } \\
\text { espécies iniciais }\end{array}$ & $\begin{array}{l}\text { Espécies iniciais } \\
\text { morrem }\end{array}$ & $\begin{array}{l}\text { Espécies tardias se } \\
\text { estabelecem }\end{array}$ & $\begin{array}{l}\text { Espécies tardias } \\
\text { persistem }\end{array}$ \\
\hline $\begin{array}{l}\text { Initial floristics } \\
\text { (Egler, 1954) }\end{array}$ & $\begin{array}{l}\text { Banco de propágu- } \\
\text { los está presente }\end{array}$ & $\begin{array}{l}\text { Todas as espécies se } \\
\text { estabelecem }\end{array}$ & $\begin{array}{l}\text { Pioneiras assumem } \\
\text { dominância; tardias } \\
\text { permanecem, mas } \\
\text { são suprimidas }\end{array}$ & $\begin{array}{l}\text { Pioneiras perecem, } \\
\text { tardias assumem } \\
\text { domância }\end{array}$ \\
\hline $\begin{array}{l}\text { Mudança na viabilida- } \\
\text { de de recursos (Drury } \\
\text { e Nisbet, 1983) }\end{array}$ & $\begin{array}{l}\text { Banco de propágu- } \\
\text { los está presente }\end{array}$ & $\begin{array}{l}\text { Espécies dominantes mudam à medida que as espécies respon- } \\
\text { dem à mudança dos recursos }\end{array}$ \\
\hline $\begin{array}{l}\text { Facilitação (Connel e } \\
\text { Slatyer, 1977) }\end{array}$ & $\begin{array}{l}\text { Pioneiras se estabe- } \\
\text { lecem }\end{array}$ & $\begin{array}{l}\text { Pioneiras modificam o ambiente } \\
\text { favorecendo tardias }\end{array}$ & $\begin{array}{l}\text { Tardias invadem e assumem a } \\
\text { dominância }\end{array}$ \\
\hline $\begin{array}{l}\text { Tolerância (Connel e } \\
\text { Slatyer, 1977) }\end{array}$ & $\begin{array}{l}\text { Espécies pioneiras e } \\
\text { tardias se estabe- } \\
\text { lecem }\end{array}$ & $\begin{array}{l}\text { Pioneiras modificam o ambiente } \\
\text { excluindo outras espécies }\end{array}$ & $\begin{array}{l}\text { Tardias toleram a competição } \\
\text { e assumem a dominância }\end{array}$ \\
\hline $\begin{array}{l}\text { Inibição (Connel e } \\
\text { Slatyer, 1977) }\end{array}$ & $\begin{array}{l}\text { Pioneiras se estabe- } \\
\text { lecem }\end{array}$ & $\begin{array}{l}\text { Pioneiras modificam o ambiente } \\
\text { de modo que tardias não podem } \\
\text { se estabelecer }\end{array}$ & $\begin{array}{l}\text { Tardias se estabelecem ape- } \\
\text { nas quando pioneiras morrem }\end{array}$ \\
\hline
\end{tabular}

Crédito: Organização do autor, a partir da proposição de Luken, 1990, p. 4

de uma coisa ou de outra [...] Os patrocinadores das teorias da causação ao nível de população argumentam, essencialmente, que, se as tendências sucessionais observadas podem ser explicadas por interações ao nível de espécie, não há necessidade de se invocarem processos a um nível superior. Por outro lado, outros teóricos argumentam que a sucessão de espécies constitui apenas uma parte do processo, e que o desenvolvimento auto-organizador é uma propriedade de ecossistemas inteiros, e que, por isso, não há necessidade de se investigar a interação das populações componentes para se explicarem tendências básicas." 21

Odum entende que a sucessão resulta de: 1) modificação do ambiente físico pela comunidade e 2) de interações de competição e coexistência no âmbito de população, supondo também que, se não houver perturbação por fatores externos, a sucessão é um conjunto bastante direcional e, portanto, previsível. Fica claro, entretanto, que a abordagem de Odum ocorre no patamar do ecossistema. Para ele, a sucessão não é uma questão de substituição de espécies, e sim de mudanças fundamentais no fluxo energético, cada vez mais energia sendo dedicada à manutenção, na medida em que acumula biomassa. A energia fixada tende a ser equilibrada pelo custo energético de manutenção, com um máximo de biomassa e função simbiótica.

O conceito de clímax significa que a comunidade chegou a um estágio final ou estável do sere. Segundo Odum², teoricamente, a comunidade é autoperpetuante 
porque está em equilíbrio em si e com o ambiente físico. Considera-se que, embora arbitrário, é conveniente reconhecer, para uma região, um único clímax climático e um número variável de clímaces locais, ou edáficos, de modo que a sucessão termina limitada por tais condições locais sem atingir o ponto final teórico. $\bigcirc$ critério normalmente utilizado para determinar o estágio sucessional é o florístico, embora Odum entenda ser mais adequado um critério funcional, como a relação produção/respiração. Ele aponta: onde prevalece uma sucessão cíclica não existe clímax no sentido de um estado autoperpetuante, razão porque alguns adotam a expressão clímax catastrófico. Outro termo empregado é disclímax (ou subclímax antropogênico, para um clímax gerado pelo homem), isto é, um clímax de perturbação em decorrência de fatores que impedem que a comunidade, embora estável, atinja um clímax climático ou edáfico.

○ conceito de clímax aplicado às florestas tropicais parece não corresponder com precisão à dinâmica dessas formações, na medida em que são mosaicos de diversos estágios sucessionais, tendo sido esse caráter das florestas tropicais primeiramente apontado por Aubreville em $1938{ }^{23}$. Isso devido ao fato de essas serem mosaicos de diversos estágios de desenvolvimento, que se sucedem na própria dinâmica da floresta e responsáveis, inclusive, pela diversidade alta que apresentam: "A hipótese mais aceita hoje é que a diversidade tropical se deve à evolução em condições intermediárias de perturbação e não em condições de equilíbrio, como se pensava anteriormente. As populações de cada espécie que compõem a flora tropical devem estar em condição de constante fluxo em função de perturbações ambientes, formando um mosaico de diferentes estágios de sucessão. Tal condição implica no constante desaparecimento local e colonização de novas populações. A resposta de uma espécie depende das características da perturbação: tamanho, duração, intensidade, freqüência e características biológicas das proximidades." ${ }^{24}$ Dessa forma, a sucessão parece ser um processo permanente de mudança dentro da floresta e, em certo sentido, cíclico, comparecendo mesmo nas fases maduras ou de clímax, como necessária à descrição desse estágio.

Budowski ${ }^{25}$ entende que o processo de sucessão envolve a substituição ordenada no tempo de uma comunidade de plantas por outra (seres), geralmente implicando em mudança na composição florística, na fisionomia e na estrutura ecológica da comunidade, tendendo, para ele, a uma situação estável. Esse autor se tornou uma referência clássica ao definir uma série de características ecológicas das espécies, conforme seu papel no processo de sucessão ecológica, que estão na base da maioria dos conceitos e práticas de recomposição.

Propõe ${ }^{26}$ haver, nas florestas pluviais tropicais americanas, relações entre o padrão de distribuição das espécies e seu estágio sucessional. As pioneiras e secundárias iniciais, indiferentes a condições climáticas e edáficas, comparecem na floresta apenas em clareiras, ou nas bordas, ou em estágios iniciais de florestas decíduas, tendo um mecanismo de dispersão extremamente eficiente. Ele nos chama a atenção para uma questão da maior importância: a distribuição de pioneiras e secundárias iniciais está tendo, em função do impacto das intervenções humanas, um notável incremento, assunto sobre o qual ainda não encontramos ênfase específica na bibliografia que temos 
consultado. As secundárias tardias apresentam deciduidade mesmo em áreas de alta pluviosidade, com ciclo de vida longo, podendo atingir grande tamanho e, eventualmente, sem chegar a regenerar-se no local. A tendência no clímax é de alta diversidade de espécies, exceto onde ocorrem fatores edáficos excepcionais.

Estudando os bosques da América tropical, Budowski ${ }^{27}$ definiu três tipos: sobre solos zonais com drenagem relativamente boa, sobre solos intrazonais ou azonais de drenagem difícil, e os bosques secundários, em geral em solos aluviais que foram explorados para agricultura ou pecuária. Divide esses bosques em secundários jovens (com menos de 25 anos) e secundários tardios (entre 25 e 100 anos). As conclusões a que o autor chega sobre as características das espécies desses grupos ecológicos (apresentadas no Quadro 3- 2) são de as espécies secundárias serem mais fáceis de manejar (menos exigentes quanto a solo e variações ambientais, com crescimento mais rápido). Por outro lado, nas fases iniciais, ocorrem herbáceas, gramíneas e arbustos difíceis de erradicar, e o tamanho dos bosques é pequeno, dificultando a regeneração natural, e a madeira das pioneiras ainda encontra pouca aplicação comercial ${ }^{28}$.

Quadro 2: Características notáveis de bosques secundários de diferentes idades em relação ao clímax edáfico de uma região, segundo Budowski

\begin{tabular}{|c|c|}
\hline Estágios iniciais & Clímax \\
\hline $\begin{array}{l}\text { Número de espécies mais reduzido, freqüentemente } \\
\text { com domínio de uma só espécie }\end{array}$ & Maior número de espécies \\
\hline $\begin{array}{l}\text { Velocidade na mudança da composição florística } \\
\text { elevada }\end{array}$ & $\begin{array}{l}\text { Diminui até chegar ao clímax, onde a estabilida- } \\
\text { de é a regra }\end{array}$ \\
\hline Pioneiras têm uma ampla distribuição geográfica & $\begin{array}{l}\text { A área de distribuição é geralmente restrita e } \\
\text { muitas espécies são endêmicas }{ }^{29}\end{array}$ \\
\hline \multirow{2}{*}{$\begin{array}{l}\text { O hábitat das pioneiras pode abarcar condições } \\
\text { muito diferentes e precárias como zonas mais áridas, } \\
\text { solos pobres, rochosos ou pantanosos }\end{array}$} & $\begin{array}{l}\text { Espécies são mais exigentes em requisitos climáti- } \\
\text { cos, edáficos e biológicos }\end{array}$ \\
\hline & A altura das comunidades aumenta até o clímax \\
\hline $\begin{array}{l}\text { Pioneiras raramente apresentam diâmetros supe- } \\
\text { riores a } 50 \mathrm{~cm} \text {. }\end{array}$ & $\begin{array}{l}\text { Diâmetros maiores se encontram em secundárias } \\
\text { tardias e no clímax }\end{array}$ \\
\hline $\begin{array}{l}\text { Há mudanças constantes entremeadas por fases } \\
\text { de relativa estabilidade na área basal, volume e } \\
\text { peso das árvores }\end{array}$ & $\begin{array}{l}\text { Área basal, volume e peso aumentam até o } \\
\text { clímax }\end{array}$ \\
\hline Estratos inferiores mais densos & Estratos inferiores menos densos \\
\hline \multicolumn{2}{|l|}{ Sistema radicular é mais superficial } \\
\hline $\begin{array}{l}\text { Copas são geralmente similares, extensas, delga- } \\
\text { das, em forma de guarda-chuva e, em geral, com } \\
\text { ramificação verticilada. Há um amplo espaço entre } \\
\text { o dossel e o estrato inferior seguinte }\end{array}$ & $\begin{array}{l}\text { Essa tendência decresce até o clímax, no qual } \\
\text { as espécies do dossel apresentam copas muito } \\
\text { variadas e, em geral, há uma intensa ocupação } \\
\text { do espaço }\end{array}$ \\
\hline $\begin{array}{l}\text { As pioneiras são muito intolerantes em todas as } \\
\text { suas fases de crescimento }\end{array}$ & $\begin{array}{l}\text { As espécies do clímax são muito tolerantes antes } \\
\text { de alcançar o dossel. As secundárias tardias } \\
\text { são intermediárias e geralmente são tolerantes } \\
\text { em sua fase jovem, tornando-se, logo depois, } \\
\text { intolerantes }\end{array}$ \\
\hline
\end{tabular}




\begin{tabular}{|c|c|}
\hline $\begin{array}{l}\text { Comunidades pioneiras, em geral, são } \\
\text { coletâneas }\end{array}$ & $\begin{array}{l}\text { No clímas as comunidades sempre são } \\
\text { incoetâneas }\end{array}$ \\
\hline $\begin{array}{l}\text { Muitas pioneiras têm sementes que podem } \\
\text { permanecer em estado latente no solo } \\
\text { sombreado durante anos, germinando quando } \\
\text { perturbação aumenta a intensidade de radiação }\end{array}$ & $\begin{array}{l}\text { As espécies do clímax têm dormência curta e } \\
\text { viabilidade muito baixa }\end{array}$ \\
\hline $\begin{array}{l}\text { A regeneração das dominantes é rara entre as } \\
\text { pioneiras }\end{array}$ & $\begin{array}{l}\text { Nas secundárias tardias a regeneração inicial é } \\
\text { abundante, mas há grande mortalidade na fase } \\
\text { jovem. No clímax todas as classes de idade estão } \\
\text { proporcionalmente representadas }\end{array}$ \\
\hline $\begin{array}{l}\text { Ganho anual em altura e diâmetro muito alto entre } \\
\text { pioneiras. Esse crescimento diminui rapidamente entre } \\
6 \text { e } 10 \text { anos, chegando ao fim antes dos } 20 \text { anos }\end{array}$ & $\begin{array}{l}\text { As espécies do clímax crescem muito lentamente, } \\
\text { mas até uma idade muito avançada }\end{array}$ \\
\hline $\begin{array}{l}\text { Pioneiras têm ciclo de vida curto, raramente superior } \\
\text { a } 20 \text { anos }\end{array}$ & $\begin{array}{l}\text { A longevidade aumenta até o clímax. As espécies do } \\
\text { clímax são longevas, ultrapassando centenas de anos }\end{array}$ \\
\hline $\begin{array}{l}\text { Entre as pioneiras, a maior proporção de árvores } \\
\text { mortas ocorre no dossel }\end{array}$ & $\begin{array}{l}\text { No clímax a maior proporção de árvores mortas } \\
\text { ocorre nos estratos inferiores }\end{array}$ \\
\hline $\begin{array}{l}\text { Frutos e sementes de pioneiras são pequenos e } \\
\text { abundantes desde muito cedo em seu ciclo de vida. } \\
\text { São adaptados para dispersão anemocórica ou por } \\
\text { pequenos animais, especialmente aves e morcegos }\end{array}$ & $\begin{array}{l}\text { No clímax, frutos e sementes são maiores, menos } \\
\text { abundantes e são disseminados, principalmente, por } \\
\text { gravidade e por animais maiores. Nas secundárias } \\
\text { tardias somente as espécies do dossel apresentam } \\
\text { dispersão predominantemente anemocórica }\end{array}$ \\
\hline A madeira é leve e mole & $\begin{array}{l}\text { A dureza e densidade da madeira aumentam até } \\
\text { o clímax }\end{array}$ \\
\hline As palmáceas, em geral, estão ausentes & $\begin{array}{l}\text { Embora possam, eventualmente, estar ausentes, tendem } \\
\text { a ser abundantes no clímax. Alguns gêneros, como } \\
\text { chamaedora, são exclusivas de condições primárias }\end{array}$ \\
\hline $\begin{array}{l}\text { As trepadeiras são abundantes entre as pioneiras, } \\
\text { nas quais são, principalmente, herbáceos ou muito } \\
\text { pouco lenhosos e cobrem estratos baixos, porém } \\
\text { raras vezes alcançam as copas altas }\end{array}$ & $\begin{array}{l}\text { No clímax há maior número de espécies, porém } \\
\text { menor número de indivíduos e muito são lenhosos e } \\
\text { grossos, alcançando as copas das árvores mais altas }\end{array}$ \\
\hline $\begin{array}{l}\text { Gramíneas, ervas e outras plantas rasteiras são } \\
\text { comuns nas fases iniciais, são intolerantes e abun- } \\
\text { dam geófitas }\end{array}$ & $\begin{array}{l}\text { No clímax o número de indivíduos diminui notavel- } \\
\text { mente e as espécies presentes são muito tolerantes }\end{array}$ \\
\hline Epífitas são raras ou ausentes & $\begin{array}{l}\text { Aumentam em abundância, riqueza, formas de vida } \\
\text { e variação de tamanho }\end{array}$ \\
\hline
\end{tabular}

Crédito: Organização do autor, a partir da proposição de Budowski, 1966, p. 282-284

As características fisiológicas das plantas são importantes no processo de regeneração da floresta tropical, pois não só as perturbações produzem uma diversidade de condições ambientais como luz, temperatura, regime hídrico, qualidade dos solos, como também a própria interação da planta com o meio produz complexas e contínuas mudanças ecológicas ${ }^{30}$. Na verdade, é próprio das florestas tropicais apresentarem gradientes e variações diárias dessas condições ambientais ${ }^{31}$. As espécies pioneiras e secundárias freqüentemente formam banco de sementes, possivelmente com longo período de dormência, aumentando a germinação com a luz, a temperatura e a concentração de nutrientes. A distribuição dos indivíduos, visível por floração, forma da copa, etc., apresenta padrões que dependem de estratégias diversas na duração, intensidade e época de floração. Floração intensa atrai muitos animais para os recursos encontra- 
dos nas florestas (tecidos, néctar...), favorecendo a polinização e possibilitando o fluxo gênico que garante a variabilidade genética da população. Pode abrir poucas flores por períodos vespertinos e noturnos, atraindo morcegos, por exemplo. Esse processo de dispersão garante a continuidade da população ${ }^{32}$.

Tais estudos remetem à necessidade de conhecimentos determinantes do processo de regeneração e sucessão ecológica que não ocorrem no nível do ecossistema (ou das propriedades emergentes). A seguir, apresentamos uma série de considerações nessa direção que, de modo algum, poderiam esgotar o assunto.

O crescimento da vegetação a partir de sementes é um dos importantes pontos a serem analisados. A colonização de novos sítios a partir da dispersão de sementes resulta da interação da "arquitetura" da semente com vento, água, gravidade ou fauna. É um estágio do ciclo de vida resistente a condições ambientais adversas, no qual a reserva nutritiva que possuem é um fator importante a determinar seu sucesso em vários tipos de ambientes. A dormência pode garantir um banco de sementes no solo. Sua viabilidade pode depender da história do sítio, do regime da perturbação e de agentes dispersores. Sua presença no solo, entretanto, não garante que existirão comunidades adultas, se a dormência não for quebrada, se forem destruídas nesse estágio ou se as plântulas e plantas não se viabilizarem por motivos vários após a germinação. Já mencionamos também que espécies presentes na vegetação poderão não estar presentes no banco de sementes ${ }^{33}$.

Mantovani chama a atenção para a importância da presença em florestas tropicais de um banco de plântulas e não apenas de sementes, pois germinam rapidamente ou são predadas por apresentarem grande quantidade de recursos nutritivos. Além disso, encontram impedimentos mecânicos à germinação, como a camada de serapilheira, ou ausência de luz a formar um ambiente muito seletivo e com poucos sítios favorávei ${ }^{34}$.

O banco de sementes é variável durante a sucessão. Como espécies iniciais produzem uma grande quantidade de pequenas sementes, há um grande número delas nos estágios iniciais ou intermediários, declinando com a sucessão ${ }^{35}$. Porém, uma vez que a viabilidade das sementes depende de um complexo de fatores, não se pode estabelecer uma regra universal. As sementes das espécies iniciais, e, em particular, as plantas anuais, podem permanecer por longos períodos no banco de sementes, até serem estimuladas por alterações na temperatura e na luminosidade, com a remoção do dossel. Ao contrário, muitas espécies arbóreas tolerantes ao sombreamento têm um pequeno lapso entre a dispersão e a germinação, podendo não formar um banco de sementes persistente.

A maior fonte de recrutamento de sementes são pássaros e outros animais. São observadas algumas características na germinação e recrutamento de sementes em florestas tropicais ${ }^{36}$. A germinação das sementes de muitas espécies da floresta secundária é aumentada pelo incremento de luz e, geralmente, é rápida nas florestas tropicais. Mas há também variações intra-específicas na velocidade de germinação.

A reprodução sexuada da vegetação, isto é, por meio das sementes, é considerada desejável por garantir uma alta variabilidade genética da população. Entretanto, 
o crescimento da população por meios vegetativos também pode ser um importante fator para sua perpetuação ${ }^{37}$. Pode ocorrer espontaneamente ou quando uma parte da planta é removida, por meio de três processos: a produção de uma planta nova nos meristemas axilares, a formação de bulbos diferentes em sua estrutura da planta mãe, ou pela regeneração de um fragmento capaz de produzir raízes adventícias ${ }^{38}$. A regeneração da floresta depende de recrutamento, sobrevivência e crescimento de grande número de espécies a diferirem em seus modos de vida e nos papéis que assumem na regeneração, com peculiaridades na germinação, adaptações de copa e folhas, regime hídrico dos tecidos, fotossíntese, resistência à predação, etc. Muitas perturbações criam grande heterogeneidade de hábitats que favorecem o recrutamento de espécies diferentes, implicando em cenários diversos de crescimento ${ }^{39}$. $\bigcirc$ padrão de crescimento esperado é de as pioneiras crescerem muito inicialmente, sendo dominantes no início, mas declinando depois, enquanto o crescimento das espécies primárias é lento, mas contínuo, até se tornarem dominantes.

Uma dimensão fundamental na compreensão do processo diz respeito à estrutura da floresta. Não entraremos nessa questão, neste artigo, desejando apenas destacar que a flora ${ }^{40}$ (estudo qualitativo) pode não dar uma descrição suficiente do que ocorre, embora seja uma condição necessária para o conhecimento e discussão da estrutura da floresta. São os estudos da estrutura da vegetação (fitosssociológicos, quantitativos) que permitirão, apoiados na identificação da flora, compreender o estágio no qual se encontra a mata, na medida em que esse estágio possa ser visto como tendência no tempo, além de permitir correlacionar esses aspectos com condicionantes ambientais. Assim, por exemplo, existência de indivíduos jovens indica recuperação e manutenção das populações. Na floresta tropical a população ocorre com poucos indivíduos em meio a uma grande quantidade de outros indivíduos, tornando muito complexa a exploração desses recursos. A eliminação de extensas áreas altera a estrutura original do mosaico e pode comprometer a manutenção de espécies mais exigentes ou que dependam de interações específicas determinadas pela própria dinâmica da floresta na interação dos seres com o ambiente físico.

As florestas tropicais são mosaicos estruturais, nas quais as clareiras são consideradas importantes para a manutenção da diversidade. Pode haver espécies de dossel que dependam de clareiras para germinar. As clareiras aumentam a riqueza da floresta tropical, gerando vários nichos a favorecerem a regeneração de espécies ecologicamente distintas. Formam microambientes com condições diversas de luz, temperatura, duração da insolação, umidade, dependendo do tamanho e da forma da clareira. Costa e Mantovani, estudando a mesma área estudada por Vuono em 1985, no Parque Estadual das Fontes do Ipiranga, concluíram que a maioria das espécies amostradas apresentava estratégia de ocupação de clareiras pequenas, "demonstrando a resiliência da floresta analisada e confirmando o predomínio de clareiras com áreas reduzidas em florestas tropicais". "O fato de muitas espécies estarem representadas em clareiras, indica a importância que os distúrbios têm na dinâmica da floresta, sendo essencial para a manutenção de muitas espécies de árvores." ${ }^{\prime 41}$ 


\section{CONCLUSÃO}

Efeitos sazonais, biológicos ou antrópicos podem prejudicar grande quantidade de espécies, gerando situações atípicas, faltando um intervalo na dinâmica da sucessão, alterando a estrutura etária da população. A vista dos aspectos expostos, a questão central é o quanto a biodiversidade tropical é exatamente decorrência desses mosaicos e, portanto, qual o comprometimento que pode ser causado a essa biodiversidade em decorrência da eliminação ou alteração em grande extensão de hábitats.

A paisagem é, portanto, uma escala determinante a ser considerada no estudo da dinâmica dos ecossistemas e de suas populações, mas desconsiderada ou pouco considerada nessas teorias até aqui expostas e tratada em outras vertentes do conhecimento ecológico, sobretudo da ecologia da paisagem. A dinâmica da paisagem é tanto de natureza ecológica quanto social, o que coloca outros problemas ainda menos investigados, quais sejam, o dos papéis das ações humanas e seu alcance na alteração das funções ecológicas.

Alterações no nível da paisagem podem comprometer processos de regeneração em curso, em decorrência, por exemplo, de alterações nos rios, em terras agrícolas próximas, urbanização de áreas, etc. Outro aspecto importante é que a regeneração, sendo um processo alogênico, não é determinada apenas no nível da dinâmica das populações no ecossistema considerado, mas é altamente influenciada pelo ambiente. $\bigcirc$ banco de sementes do solo dificilmente será o responsável suficiente da regeneração e de sua continuidade, dependendo ou de manejo ou da existência de áreas adjacentes que sirvam como fornecedoras de propágulos. $\bigcirc$ próprio tamanho, forma, inserção na paisagem, além de sua história, são decisivos no processo sucessório, como evidencia a teoria dos fragmentos (das "ilhas") e dos corredores - o que mostra a necessidade de novos desenhos para as estruturas que o trabalho humano agrega ao território.

Abre-se, portanto, um campo de investigações o mais complexo e exige estudos transdisciplinares, ainda mais tendo em vista que sua aplicabilidade ocorre, necessariamente, dentro de um quadro de políticas públicas ${ }^{42}$ e práticas sociais condicionadas por valores e ideologias que parametrizam a tomada de decisões, a revisão de conceitos, a efetividade das ações. Sobretudo se as áreas de estudo forem os remanescentes urbanos de vegetação nativa ou em suas imediações ${ }^{43}$.

A interação desses processos no desenho do ambiente humano rural e urbano, por um lado, é determinado por processos de ordem social ${ }^{44}$, econômica e cultural que não podem ser desprezados. Por outro lado, não se pode, igualmente, desprezar o avanço dos conhecimentos em curso sobre as dinâmicas da natureza na transformação do sítio para usos humanos, determinando-se, assim, ao lado dos direitos dos cidadãos, da participação social e de outros temas candentes atuais, a natureza do projeto civilizatório contemporâneo a par da barbárie determinada pelos processos de exclusão subjacentes a esse projeto.

Claro está que não se pensa, aqui, no arquiteto produzindo pesquisas básicas de cunho ecológico, mas, entendendo essa dinâmica, seja capaz de transpô-la para ações 
concretas de intervenção no território. Este artigo apenas introduz alguns fundamentos conceituais necessários para ações na paisagem, fornecendo acesso a uma base de conhecimentos de outras áreas as quais deverão condicionar, cada vez mais, opções de desenho. As discussões abertas por essa perspectiva são efetivamente grandes, sobretudo quando consideramos remanescentes em áreas urbanas ou envoltórias de grandes aglomerações.

Seria inadmissível as ações continuarem a ocorrer dentro dos paradigmas e práticas vigentes, à vista do conhecimento científico já disponível sobre a dinâmica dos processos naturais. $\bigcirc$ entendimento dos processos ecológicos, para os quais as teorias sobre sucessão contribuem tanto conceitualmente quanto com implicações práticas para manejo, transcende, hoje, a questão interna das unidades de conservação e tornase um pré-requisito para gestão territorial urbana. Se, no doutorado, investigamos o estado da arte e inserimo-lo em ampla discussão da cultura no trato da vegetação, a pesquisa atual que iniciamos sobre potencialidades de paisagem, no âmbito da metrópole paulistana, visa agregar esse conhecimento técnico e sua perspectiva crítica no enfrentamento integrado das condições ambientais e paisagísticas na região da Reserva da Biosfera do Cinturão Verde de São Paulo, tornando possível, assim, a investigação da aplicação desses fundamentos como parte de um método de análise a objetivar a gestão do espaço urbano.

\section{Notas}

(1) Citado por Dajoz, 1973, p. 300, ênfase nossa.

(2) Sandeville Jr., 1999.

(3) Matthes e Martins, 1996, p. 20, indicam que o conceito de sucessão foi desenvolvido, primeiramente, pelos botânicos De Candolle, De La Malle, Dureau, Hult e Vauupell, tendo, em 1893, Warming apresentado uma visão geral do assunto. Segundo os autores, foram Cowles, em 1999, e Clements, em 1916, que "fizeram o uso mais extenso do conceito de sucessão, estabelecendo uma variada terminologia para as distintas séries e etapas".

(4) "Clements inventa esses instrumentos e procedimentos experimentais [como o quadrado, círculo de migração e transsecto] pois está certo de que a vegetação não tem só uma estrutura mas também um desenvolvimento específico, que nela trata-se de fenômenos repetitivos, e que portanto é possível entendê-los pelo estabelecimento de leis científica." Acot, 1990, p. 47.

(5) Segundo Dajoz, 1973, os ecólogos europeus procuraram um outro entendimento do conceito de clímax, determinado por condições edáficas (policlímax). Dajoz (1973, p. 303) menciona ainda que uma sucessão secundária pode conduzir a um disclímax, diferente do clímax que existia antes da perturbação.

(6) "... a vegetação é essencialmente dinâmica, mas por reagir fortemente sobre o habitat, ela mostra uma constante tendência a se tornar estática.", Clements, citado por Acot, 1990, p. 47.

(7) Luken, 1990, p. 3: "The approach of Clements - that is, separation of succession into component processes or events - has been taken by different researches to explain succession under a variety of environmental conditions." Walter (1985, p. 178) refere-se à formulação de Clements: "This is a purely theoretical conception and in no way reflects reality." e: "His dynamic aproach became the orthodox view of plant geography in the USA and was largely adopted by Tansley and Braun-Branquet as well. ... is a good example of the dangers inherent in theorizing in ecology without wide field experience."

(8) "ele considerava que uma comunidade repete no seu desenvolvimento a seqüência de estádios de desenvolvimento de um organismo individual, e que todas as comunidades numa dada área climática desenvolvem-se em direção a um único clímax (a idéia de monoclímax...), idéias que hoje recebem pouco destaque ou que foram modificadas; porém, a tese principal de Clements - de que a sucessão ecológica é um processo de desenvolvimento e não apenas uma sucessão de espécies, cada uma das quais agindo sozinha - permanece como uma das teorias unificadoras mais importantes da ecologia." Odum, 1988, p. 298. 
(9) Segundo Finegam, 1984, citado por Nascimento, 1994, p. 1.

(10) Walter, 1985, p. 179.

(11) Walter, entendendo que a sucessão secundária só ocorre após eventos catastróficos, reconhece um processo próprio das florestas virgens - um ciclo dinâmico interior, que não poderia ser considerado como sucessão. Ele exemplifica com uma floresta virgem de 300 ha. na Áustria, formada por três gêneros, revelando o tipo de dinamismo que ocorre em uma floresta temperada. $\bigcirc$ estrato inferior forma um micromosaico em constante mudança em função de condições ambientais. Ocorre também um processo mais geral - um ciclo da vegetação em algumas fases devido à queda de árvores e à estrutura variada do estrato arbóreo, com diferenças de mais de 300 anos entre os indivíduos. Walter, 1985, p. 180

(12) Koch; Ward, 1994

(13) Luken, 1990, p. 5.

(14) Mattes; Martins, 1996

(15) Finegan, B. Forest. Succession. Londres, v. 312, p. 109-114, 1984.

(16) Odum, 1988, p. 296. Segundo o autor, o conceito de a sucessão resultar apenas da interação de indivíduos remonta a Gleason em 1926: The individualistic concept of plant succession. A premissa básica expressa por Pickett em 1976 é de estratégia evolutiva (seleção, competição) e características do ciclo vital determinarem a posição da espécie em gradientes sucessionais a mudarem constantemente, devido a perturbações e gradientes físicos. Haveria, entretanto, abordagens intermediárias, como a de Glasser, em 1982, as quais entende que, na fase inicial, a colonização seria casual por organismos oportunistas, enquanto em etapas posteriores seria mais organizada e direcional.

(17) Mattes; Martins, 1996, p. 21.

(18) Mattes; Martins, 1996, p. 22, tomando como base também Whittaker, R. H. A consideration of climax theory: The climax as a population and pattern. Ecol. Monog., Washington, v. 23, p. 42-78, 1953.

(19) Citado por Mattes e Martins, 1996, p. 23.

(20) Esse autor parece considerar a teoria de Connel e Slatyer a explanação recente mais influente. Connel e Slatyer, em 1977, apresentaram três modelos: facilitação, tolerância e inibição. Luken, assim, adota como o modelo que melhor descreve a realidade - o da inibição. Inibição "is where established species inhibit the invasion and growth of all potential competitors during the entire duration of a successional pathway. There was much evidence in support of this model. Many failed attempts to speed the invasion of trees into established vegetation will attest to the fact that inhibition is a reality". Luken, 1990, p. 5. O modelo da facilitação preconiza que as espécies do início do sere mudam as condições de existência, preparando o caminho para invasores posteriores; o modelo de inibição preconiza que as primeiras espécies resistem à invasão até serem substituídas por causa da competição, predação e perturbação, segundo explicação desses modelos por Odum, 1988, p. 297. A opção de Luken pelo último modelo reflete uma tensão teórica na abordagem da sucessão, entre enfoques que privilegiam os processos no âmbito do ecossistema (biocenose) e aqueles que privilegiam aspectos ligados ao indivíduo e à população no processo de sucessão.

(21) Odum, 1988, p. 296

(22) Odum, 1988.

(23) "A idéia de que as florestas tropicais são mosaicos estruturais data de 1937, quando Abreuville (1937) propôs sua teoria de regeneração de mosaicos. Desde então, estas formações têm sido descritas como mosaicos de clareiras criadas por queda de árvores, diferindo em idade, tamanho e composição de espécies (BROKAW, 1985)." Costa e Mantovani, 1992, p. 178. Segundo Mattes e Martins, 1996, os primeiros estudos de sucessão em florestas pluviais tropicais foram os de Cook em 1909, Beebe e Brow em 1919, Bernoist em 1924, Stanley em 1928.

(24) Viana, 1987, p. 31.

(25) Budowski, 1963.

(26) Budowski, 1965.

(27) Budowski, 1966.

(28) Espécies desses grupos apresentam taxas elevadas de fotossíntese, respiração e transpiração, produção contínua de folhas com alta taxa de renovação, crescimento rápido, baixa densidade da madeira, folhas grandes, florescem logo e por longo período. Apresentam respostas rápidas a mudanças no âmbito dos recursos, alto potencial de aclimatação e alta suscetibilidade a herbivoria e patógenos.

(29) Resultado obtido por Lucia Rossi no estudo florístico da Mata da Cidade Universitária da USP (Cuaso - Cidade Universitária Armando Salles de Oliveira), em São Paulo, apresentaram grande número de espécies de distribuição geográfica muito ampla, características, talvez, do tipo de vegetação, mas talvez também indicando perda da diversidade na área. Estudos na Mata Atlântica têm encontrado grande número de endemismos.

(30) "Successful management of tropical forests and their continued use as a renewable resource must be based on a good understanding of the basic biology of the component species and their role in the process of regeneration." Bazzaz, 1991. 
(31) Os gradientes verticais microclimáticos influem no balanço energético individual das folhas e em sua capacidade de fixação de carbono, segundo Bazzaz, 1991. As condições de temperatura e insolação podem variar muito para a mesma folha ao longo do dia, variando também o comportamento estomático. $\bigcirc$ tamanho da folha tende a aumentar com a precipitação e a diminuir com a queda de umidade do solo ou de nutrientes ao longo de gradientes edáficos, tendendo também a serem maiores nos estratos inferiores do que no dossel. Também é esperado que espécies iniciais tenham folhas maiores do que as tardias. $\bigcirc$ ângulo de inclinação da folha pode ser característico em espécies quando expostas ao sol, diminuindo a área de exposição foliar. Diversas outras adaptações e comportamentos podem ocorrer em relação ao suprimento hídrico, à fotossíntese (em geral espécies heliófitas possuem taxas máximas em relação às primárias do dossel e ombrófilas), arquitetura da planta, velocidade de crescimento em altura e diâmetro. A herbivoria pode ter um importante papel no processo regenerativo, no sentido de comprometer a produção, trazer alterações à arquitetura da planta ou causar a morte.

(32) Segundo Mantovani (anotações de aula), conhecemos apenas alguns padrões, como, por exemplo, do palmito que apresenta floração massiva para atrair grande quantidade de animais. A maioria das plantas de uma floresta é auto-incompatível, nas regiões tropicais e dependentes de animais para polinização. Há plantas como aristolochia que apresentam uma seqüência na qual uma única flor está apta seqüencialmente, atraindo, pelo odor, moscas que só conseguem sair quando, pela maturação dos órgãos masculinos, os pelos voltados para baixo ficam flácidos, permitindo sua saída e carregando os grãos de pólen. Passiflora apresenta a mesma estratégia de abertura seqüencial das flores e possui nectário. No processo sucessional, em geral, espécies iniciais são dispersas pelo vento e depois por animais. Solanum apresenta frutos na ponta dos ramos disponíveis para pássaros em vôo, como os morcegos. Há plantas polinizadas por grupos de animais e aquelas que dependem, para a germinação, de a semente passar pelo trato digestivo de animais. Agave, na restinga, apresenta formação de indivíduos no eixo da inflorescência, que cai, levando-os para longe da planta matriz. Mecanismos de defesa (folhas duras, com indumento, com defesas tóxicas) podem levar a uma especialização dos predadores. A sazonalidade também influencia nos ciclos de animais (se a dormência coincide com floração, pode haver explosão da população de animais). Segundo Mantovani, espécies mutualistas chaves supõem uma relação de dependência mútua e obrigatória, mas o que pode haver é uma diminuição de densidade. $\bigcirc$ palmiteiro é dito mutualista, mas é generalista. $O$ termo correto, segundo o estudioso, seria espécie-chave em uma comunidade, determinante de uma série de relações no sistema. Polinizador e predador de topo pode ser espécie chave, se exerce uma influência de equilíbrio no ecossistema como um todo. Mutualismo existe entre espécies de orquídeas e vespas; embora a vespa seja independente da orquídea, esta é dependente da vespa para reprodução, não configurando a categoria mutualista chave. Na Mata Atlântica, myrtaceae pode ser uma espécie chave, a florescer na mesma época, com enorme quantidade de frutos não maiores que os do palmito, em todos os seus muitos gêneros, tornando-se um recurso abundante em certas épocas do ano.

(33) Koch; Ward, 1994.

(34) Plantas ruderais apresentam de 34.000 a 75.000 sementes $/ \mathrm{m}^{2}$, florestas pluviais tropicais - 170.000 a 900.000 sementes $/ \mathrm{m}^{2}$, secundárias de 5 anos - 1.900-3.900 sementes $/ \mathrm{m}^{2}$, em estágios iniciais - 1.20013.200 sementes $/ \mathrm{m}^{2}$, segundo Mantovani, anotações de aula.

(35) Budowski, 1966.

(36) Bazzaz, 1991. Espécies pioneiras e iniciais florescem cedo no ciclo de vida e, usualmente, produzem sementes anualmente. Em áreas com estação meio seca, tendem a frutificar no fim da seca. Onde a sazonalidade é severa, tendem a concentrar a frutificação no início da estação seca. Geralmente, a longevidade da semente é baixa nas florestas tropicais. Entretanto, a longevidade das sementes é geralmente mais alta para pioneiras do que para espécies tardias e, naquelas, o banco de sementes pode ser a maior fonte de regeneração. Em contraste com essas, sementes da maioria das espécies primárias não têm dormência. $\bigcirc$ rebrotamento é comum nas árvores tropicais, mas fogo severo o reduz substancialmente. Fogo intenso e erosão destroem o banco de sementes e a regeneração passa a depender de migrantes.

(37) "Because succesion involves gradual changes in disturbance regimes and environmental conditions, much effort has been devoted to finding trends in seed production that can be expected during succession. The search for trends has indeed produced some generalizations. For example, a number of studies concluded that early-successional species allocate a greater share of annual production to reproductive structures such as flowers, fruits, and seeds than do species from late-successional stages (...). In addition, late-successional species have higler root/total biomass ratios than early-successional species (Newell and Tramer, 1978), presumably indicating more vegetative reproduction or below ground storage of energy. Such generalizations of changing sexual reproductive effort during succession are typically based on few species (Abrahamson, 1979) and often it is questionable whether the sites (habitats?) chosen for study actually represent a successional pathway. Instead of searching for a generalized trend in seed production during succession, it may be better to determine how seed production and vegetative growth interact. This has important consequences for management activities especially if one is attempting to eliminate reprodution from seed." Luken, 1990, p. 47.

(38) Muitas árvores apresentam essa característica, muito freqüente em matas ciliares e no cerrado. A viabilidade genética seria pequena, mas contam com vantagens como aumentar a chance de sobrevivência do indivíduo formado vegetativamente, que atinge mais rápido a fase adulta (isto é, reproduz mais rápido) e, provavelmente, o pool gênico é favorável às condições ambientais existentes enquanto essas se mantiverem. A reprodução 
vegetativa possibilita custos mais baixos na recuperação, porém tende a um padrão de distribuição espacial agregado. Como o investimento do organismo é alto, há pouca reprodução sexuada. A distribuição das plantas na paisagem é fortemente afetada pelo padrão de reprodução vegetativa, podendo produzir padrões diversos. As alterações ambientais podem criar situações em que a regeneração da população ocorra quase inteiramente dependente da reprodução vegetativa.

(39) Mattes; Martins, 1996/Costa; Mantovani, 1992.

(40) Por flora entendemos o conjunto de entidades taxonômicas de uma região. O termo difere de vegetação, na medida em que esta se refere ao conjunto de vegetais em certo local, condicionados por clima e geologia e são descritos por sua estrutura e fisionomia, além da composição florística. A flora e a vegetação resultam de causas antigas que produziram alterações de clima, pedologia, fauna e migrações.

(41) Costa; Mantovani, 1992, p. 183. O estudo, entretanto, não considerou a distribuição dessas espécies na estrutura da mata.

(42) Vieira e Bredariol, 1998, distinguem políticas públicas (legislação, leis e orçamentos, representação e participação) de políticas de governo (circunscritas a um mandato específico). Adotando opinião de Abreu, 1993, seriam "mediações político-institucionais" de diversos atores sociais e seriam implementadas por instituições públicas.

(43) Sandeville, 1996. Esse assunto faz parte, também, de minha atual pesquisa em desenvolvimento em que se investiga a problemática metodológica da interdependência de escalas de atuação que considerem potenciais de paisagem na região metropolitana de São Paulo e arredores, para o que os conceitos aqui apontados são conhecimento indispensável.

(44) Diegues, 1994, questiona o que designou de "mito da natureza intocável", ou seja, o modelo de Unidades de Conservação surgidos a partir da criação dos parques nacionais norte-americanos a partir de meados do século 19, que têm como postulado a exclusão do homem do conceito de natureza. A importância das comunidades tradicionais na preservação das unidades de conservação vem sendo reconhecida por organismos internacionais há pelo menos duas décadas, e leva a uma revisão dos conceitos de gestão e inclusão social dessas unidades. Recentemente, temos visto, no país, inúmeros conflitos decorrentes da questão fundiária dessas unidades e de interesses contrapondo, em luta armada, povos indígenas e fazendeiros.

\section{Bibliografia}

ACOT, Pascal. História da ecologia. Rio de Janeiro: Campus, 1990.

BAZZAZ, F. A. Regeneration of tropical forests: physiological respouses of pioneer and secondary species. In: GOMEZ-POMPA, A.; WHITMORE, T. C.; HADLEY, M. Rain forest regeneration and management. Nova Jersey: The Pathernon Pb. Group Limited, 1991.

BUDOWSKI, Gerardo. Distribution of tropical american rain forest species in the light of successional process. Turrialba: São José, v.1, n. 15, p. 42-44, 1965.

Forest succession in tropical lowlands. Turrialba: São José, v. 1, n. 13, p. 42-44, 1963.

Los bosques de los trópicos húmedos de América. Turrialba: São José, v. 3, n. 16, p. 278-285, 1966.

COSTA, Marcelo Pires da; MANTOVANI, Waldir. Composição e estrutura de clareiras em mata mesófila na bacia de São Paulo, SP. In: 2 CONGRESSO NACIONAL SOBRE ESSÊNCIAS NATIVAS, São Paulo. Anais... São Paulo: Secretaria de Meio Ambiente, 1992.

DIEGUES, Antonio Carlos Sant'Ana. O mito moderno da natureza intocada. São Paulo: Nupaub-USP, 1994.

$\mathrm{KOCH}$, J. M.; WARD, S. C. Establishment of understorey vegetation for rehabilitation of bauxite-mined areas in the jarrah forest of Western Australia. Journal of Environmental Manegement, Nova York, v. 41, p. 1-15, 1994.

LUKEN, James O. Directing ecological succession. Nova York: Chapman and Hall, 1990.

MATTES, Luiz Antonio Ferraz; MARTINS, Fernando Roberto. Conceitos em sucessão ecológica. Rev. Bras. Hortic. Ornam, Campinas, v. 2, n. 2, p-19-32, 1996.

NASCIMENTO, Francisco Haroldo Feitosa do. A sucessão secundária inicial na Mata Atlântica sobre a serra de Paranapiacaba, Ribeirão Grande, SP. 1994. Dissertação (Mestrado) - Instituto de Biociências, Universidade de São Paulo, São Paulo, 1994.

ODUM, Eugene P. Ecologia. Rio de Janeiro: Guanabara, 1988. 
ROSSI, Lucia. A flora arbóreo-arbustiva da mata da reserva da Cidade Universitária Armando Salles de Oliveira, São Paulo, SP. 1987. Dissertação (Mestrado) - Instituto de Biociências, Universidade de São Paulo, São Paulo, 1987.

SANDEVILLE JR., Euler. Áreas naturais remanescentes em centros urbanos. In: I SIMPÓSIO DE CIÊNCIAS DA ENGENHARIA AMBIENTAL, 1996, São Paulo. Anais... São Paulo: EESCUSP, 1996.

. As sombras da floresta. Vegetação, paisagem e cultura no Brasil. 1999. Tese (Doutorado) - Faculdade de Arquitetura e Urbanismo, Universidade de São Paulo, São Paulo, 1999.

VIANA, V. Ecologia de populações florestais colonizadoras e recuperação de áreas degradadas. In: SIMPÓSIO SOBRE ECOSSISTEMAS DA COSTA SUL E SUDESTE BRASILEIRA, 1987, São Paulo. Anais... São Paulo: Aciesp, v. 1, 1987.

VIEIRA, Liszł; BREDARIOL, Celso. Cidadania e política ambiental. Rio de Janeiro: Record, 1998.

WALTER, Heinrich; BRECKLE, Siegmar-W. Ecological systems of the geobiosphere. Nova York: Spring-Verlag, 1985. 